\title{
GRAPHICAL ANALYSIS OF PERFORMANCE OF A VIBRATORY BOWL FEEDER FOR FEEDING BOTTLE CAPS
}

\author{
Manas Choudhary ${ }^{1}$, Rishabh Narang ${ }^{2}$, Pradeep Khanna ${ }^{3}$ \\ ${ }^{1}$ Student, Department of Mechanical Engineering, Delhi Technological University, New Delhi, India \\ ${ }^{2}$ Student, Department of MPAE, Netaji Subhas Institute of Technology, New Delhi, India \\ ${ }^{3}$ Associate Professor, Department of MPAE, Netaji Subhas Institute of Technology, New Delhi, India
}

\begin{abstract}
Automation in manufacturing industry has now become essential as it helps meeting the ever-increasing demands quantity, quality, consistency and precision. In automated production lines, synchronization of different processes is of utmost importance to achieve the predetermined cycle times. Automation not only has resulted in the cost reduction but it has also resulted in wastage reduction. Assembly lines are extensively used in mass production units where economy of scales is exploited to spread over the cost of production over a large batch size. These assembly lines actually streamline the movement of product from one assembly station to the other in predetermined sequence so as to meet the deadlines. Feeders form an integral part of automated assembly and production lines. The present study is aimed at graphically analysing the performance of a vibratory bowl feeder with varying sizes of laminated bottle caps used in the pharmaceutical industry and other consumer goods industries. In this study, the desired outcome was the feed rate, and the various input parameters were - part population, part size, and frequency of vibratory bowl feeder. Results obtained from the experiment were analysed and conclusions were drawn to explain the effects of various parameters and to predict the behaviour of the feeder.
\end{abstract}

Keywords: Automation, Feeder, Cycle time, Feed rate, Graphical Analysis. -****

\section{INTRODUCTION}

A feeder is a machine used to feed or load any kind of material, chemical or product to the assembly line, manufacturing stations or wherever necessary. [1]

The feeder selection is a key in success related to achieve desired feeding. Hence, different types of Feeders have been made to cater to different kinds of feeding requirement which are: [2]Centrifugal Feeder, Vibratory Feeder, Linear Feeder, Flex Feeder, Step Feeder and Elevator Feeder.

The feeder used during this experiment is Vibratory Bowl Feeder. It is an instrument that uses vibration to feed material. It uses both vibration and gravity to move materials. Gravity is used to determine the direction, either down, or down and to a side, and then vibration is used to move the materials. They are mainly used to transport a large number of smaller objects.

Vibratory bowl feeders are the commonly used feeding aides used to feed components in Industrial Assembly lines. They are self-contained systems, comprising of a specially designed bowl contains randomly placed components. This bowl is mounted on a vibrating drive unit facilitated by a variable-amplitude control box. The drive unit vibrates the bowl, forcing the parts to move up a circular, inclined spiral track. The track is designed to sort and orient the parts in consistent, repeatable positions. The track length, width, and depth are carefully chosen to suit the application and component shape and size. Special track coatings are applied according to shape size and material of the parts which aids traction, damage to the product and lower acoustic levels. A variable frequency control box is used for controlling the vibration of the bowl feeder [3]. In the present investigations, a vibratory bowl feeder has been used owing to its ability to handle a variety of components and ease of operation. A number of research articles were referred to which have carried out research on different types of components on vibratory bowl feeder.

Jain et. al. [4] optimised the performance of vibratory bowl feeder by applying the Taguchi approach and found that part population had a negative effect on feed rate whereas, frequency had a positive effect on feed rate. Initially the effect of part size was negative but due to its interaction with frequency and part population, it became positive after a while.

In the investigation carried out by Jindal et. al. [ 5 \&6] graphical and mathematical analysis of vibratory bowl feeder using clip shaped components revealed that the highest frequency with the highest part population gave the maximum feed rate for the smallest part size in graphical analysis.

According to Chauhan et. al. [7], a factorial approach to study the effects of various parameters on vibratory bowl feeder gives satisfactory results. 
Bhagat et. al. [8\&9], analysed graphically and mathematically, the behaviour of vibratory bowl feeder for feeding headed components and concluded that the developed model could estimate the magnitude and direction of the effects of variation in factors as well as predicts the effects of their mutual interactions.

\section{EXPERIMENTAL SETUP}

Figure 1 shows the experimental setup used for this investigation. The setup has a frequency regulation unit which allows stepless control of frequency of vibration of the bowl. The bowl is mounted on a vibrating drive unit. The setup consists of a vibratory bowl feeder with a bowl diameter of $300 \mathrm{~mm}$ with tracks of $20 \mathrm{~mm}$ width running along the wall in a spiral. The components selected for the experiments were bottle caps of 3 different sizes viz. $16 \mathrm{~mm}$, $19 \mathrm{~mm}$ and $22 \mathrm{~mm}$ respectively. A number of trial runs were conducted for the purpose of identification of important input parameters and determination of their operating ranges. As shown in table-1.

Table 1: Input parameters and their operating limits

\begin{tabular}{|l|l|l|l|}
\hline PARAMETERS & UNIT & $\begin{array}{l}\text { LOWER } \\
\text { LIMIT }\end{array}$ & $\begin{array}{l}\text { UPPER } \\
\text { LIMIT }\end{array}$ \\
\hline FREQUENCY & $\mathrm{Hz}$ & 45 & 50 \\
\hline PART SIZE & $\mathrm{Mm}$ & 16 & 22 \\
\hline $\begin{array}{l}\text { PART } \\
\text { POPULATION }\end{array}$ & units. & 45 & 135 \\
\hline
\end{tabular}

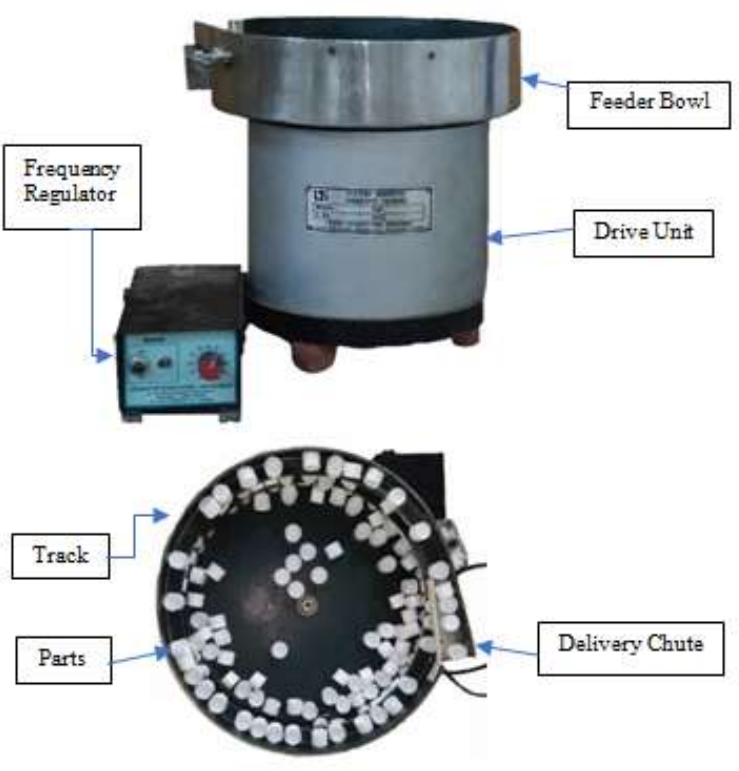

Fig 1: The experimental set up

\section{CONDUCTING THE EXPERIMENTS}

Analysis was done by using OFAT (One factor at a time) based on 3 input parameters of which 2 factors were kept constant and the third was varied. Hence, all the 3 parameters were varied one by one and a total of 27 readings were obtained.

The experiments were conducted by using one factor at a time technique. Even though this technique does not take into account the interaction effects and hence it cannot precisely predict the outcome of an experiment. However, it is still better than random experimentation and successfully gives a brief idea of the performance of the unit, to some extent, and the study can be used as a preliminary to further conduct elaborated analysis on the unit.

Input parameters were varied at three levels the lowest, intermediate and the highest. 3 runs were conducted for each of the 27 readings taken, in order to minimise the experimental errors as shown in table 2 .

Table 2: Experimental Observations

\begin{tabular}{|c|c|c|c|c|c|c|}
\hline PART SIZE & PART POPULATION & FREQUENCY & \multicolumn{3}{|c|}{ FEED RATE (PARTS/MIN) } & MEAN FEED RATE \\
\hline 16 & 45 & 45 & 67 & 73 & 68 & 69 \\
\hline 16 & 45 & 47.5 & 98 & 101 & 90 & 96 \\
\hline 16 & 45 & 50 & 46 & 46 & 49 & 47 \\
\hline 16 & 90 & 45 & 127 & 134 & 125 & 129 \\
\hline 16 & 90 & 47.5 & 164 & 165 & 170 & 166 \\
\hline 16 & 90 & 50 & 130 & 136 & 141 & 136 \\
\hline 16 & 135 & 45 & 129 & 136 & 132 & 162 \\
\hline 16 & 135 & 47.5 & 197 & 191 & 200 & 196 \\
\hline 16 & 135 & 50 & 185 & 178 & 184 & 182 \\
\hline 19 & 45 & 45 & 63 & 66 & 65 & 65 \\
\hline 19 & 45 & 47.5 & 73 & 70 & 79 & 74 \\
\hline 19 & 45 & 50 & 101 & 89 & 94 & 95 \\
\hline
\end{tabular}




\begin{tabular}{|l|l|l|l|l|l|l|}
\hline 19 & 90 & 45 & 106 & 108 & 111 & 108 \\
\hline 19 & 90 & 47.5 & 123 & 128 & 119 & 123 \\
\hline 19 & 90 & 50 & 149 & 142 & 158 & 150 \\
\hline 19 & 135 & 45 & 114 & 102 & 99 & 105 \\
\hline 19 & 135 & 47.5 & 152 & 139 & 143 & 145 \\
\hline 19 & 135 & 50 & 217 & 213 & 203 & 211 \\
\hline 22 & 45 & 45 & 62 & 58 & 61 & 60 \\
\hline 22 & 45 & 47.5 & 47 & 45 & 42 & 45 \\
\hline 22 & 45 & 50 & 40 & 42 & 45 & 42 \\
\hline 22 & 90 & 45 & 86 & 81 & 78 & 82 \\
\hline 22 & 90 & 47.5 & 102 & 106 & 97 & 102 \\
\hline 22 & 90 & 50 & 76 & 79 & 77 & 77 \\
\hline 22 & 135 & 45 & 101 & 98 & 94 & 100 \\
\hline 22 & 135 & 47.5 & 124 & 116 & 119 & 120 \\
\hline 22 & 135 & 50 & 71 & 68 & 73 & 71 \\
\hline
\end{tabular}

\section{RESULTS AND DISCUSSION}

The results obtained after conducting the experiments were plotted in the form of graphs as shown in figures 2,3,4.

The interpretation of these graphical representations is given as below

\subsection{Effect of Frequency}

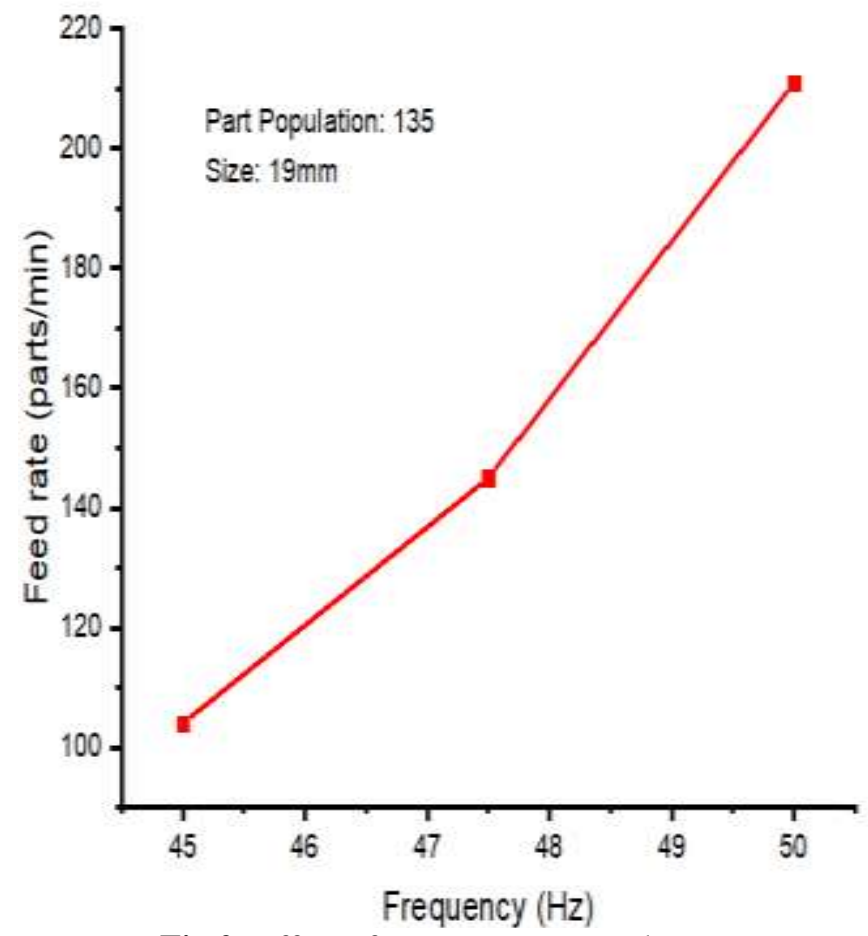

Fig 2: Effect of Frequency on Feed rate

Fig. 2 shows the effect of frequency on feed rate. As it is evident that the feed rate increased with increase in frequency, the increased agitation of the components might be responsible for pushing the components towards the delivery chute at a faster rate resulting in the increment in feed rate.

\subsection{Effect of Part Size}

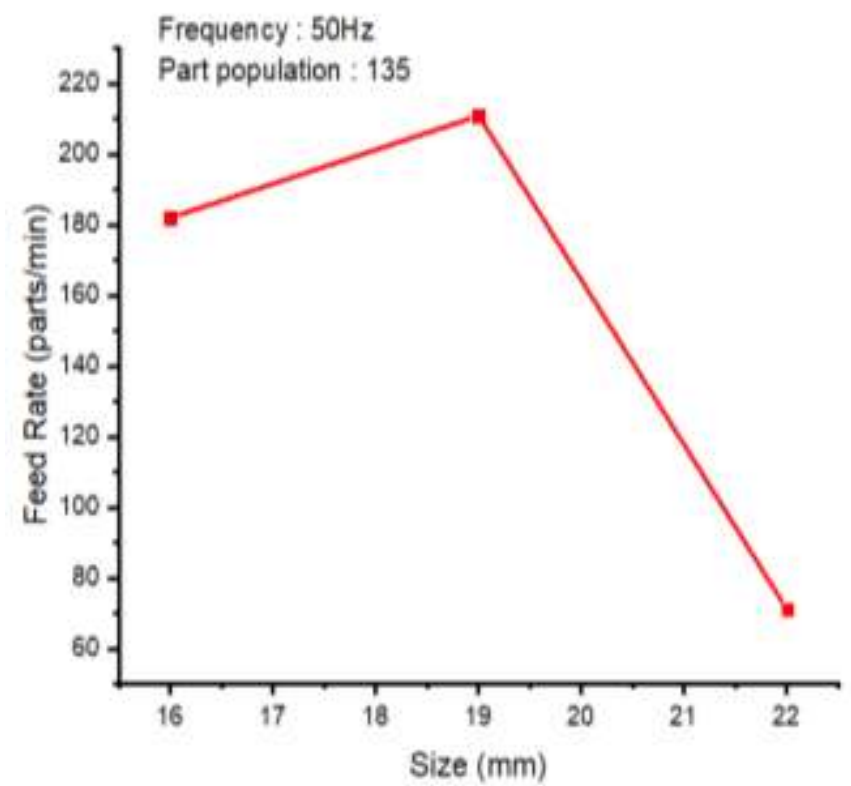

Fig 3: Effect of Part size on Feed Rate

Fig. 3 shows the relation of feed rate per minute and part size There is an increment in feed rate as part size is increased from $16 \mathrm{~mm}$ to $19 \mathrm{~mm}$, as was predicted. with increase in size, another parameter, part mass changed. Increment in both these parameters resulted in more agitation, causing an increase in the pushing tendency of the components. Larger the part size higher the feed rate. This proportionality explains the trend satisfactorily.

However, on increasing part size from $19 \mathrm{~mm}$ to $22 \mathrm{~mm}$ there's a decrease in the feed rate, which seems to contradict the explanation offered previously. This can be explained by taking the fall-back factor into consideration. The width of the circular track inside the feeder bowl is $20 \mathrm{~mm}$. Even 
though $22 \mathrm{~mm}$ parts are adequately stable on the $20 \mathrm{~mm}$ wide track in rest state, their stability decreases on being subject to agitation. A major fraction of the component population falls back into the bowl when the feeder is in active state. This explains the trend as observed in fig 3 .

From the observed trend, we can infer that, the feed rate increases with increase in part size while the part size remains less than the width of the track, after which collapsibility factor comes in. Hence the optimum feed rate can only be obtained with the largest available part size that is smaller than the track width.

\subsection{Effect of Part Population}

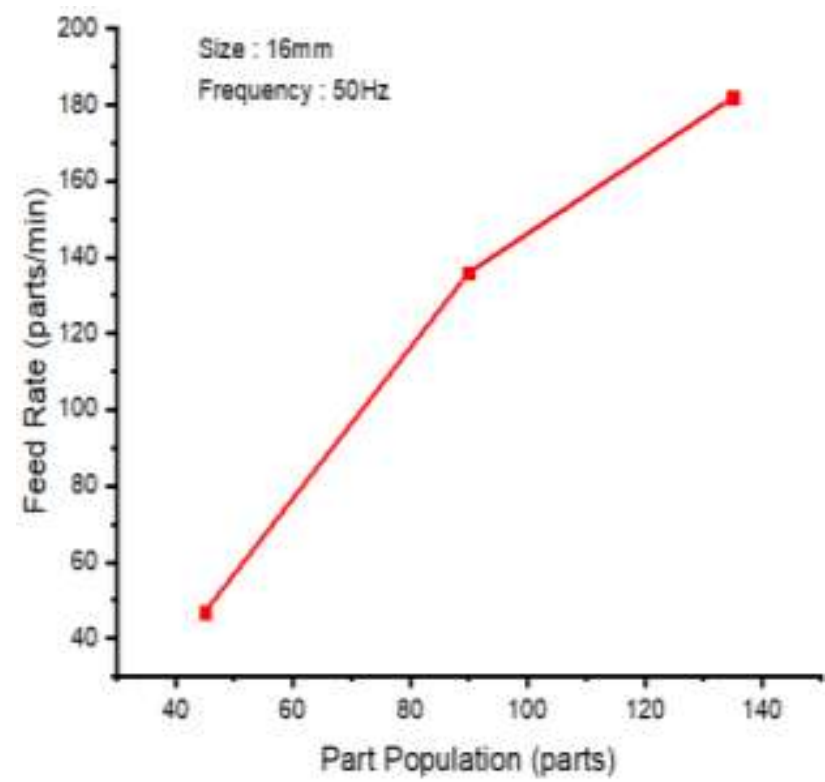

Fig 4: Effect of Part population on feed rate.

Fig. 4 shows the relation of feed rate and part population. It is evident from the graph that feed rate increases almost linearly with increase in part population. This can be explained by the fact that with increase in part population, componentsinteract with each other more frequently compared to when same degree of agitation is generated for lower part population. More interaction means more parts pushing each other, resulting in increased feed rate.

\section{CONCLUSION}

The graphical analysis of the experimentation conducted show that maximum feed rate of 211 parts/min is obtained at part population of 135 units, frequency $50 \mathrm{~Hz}$ and part size $19 \mathrm{~mm}$.

\section{ACKNOWLEDGEMENT}

The authors would like to thank Mr Pradeep Khanna, Associate Professor, Division of Manufacturing Processes and Automation, Netaji Subhas Institute of Technology, without whose guidance and timely support, this paper and the complete experiment would not have been possible.

\section{REFERENCES}

[1] Slide no. $\quad$ - 2 https://www.slideshare.net/faugee/feeder-equipment, accessed on 29 June, 2018.

[2] http://www.hoosierfeedercompany.com/vibratoryrotary-feeder-insights/what-are-the-different-typesof-parts-feeder-systems , accessed on 29 June, 2018.

[3] https://www.rnaautomation.com/products/feedingand-handling/vibratory-feeders/ , accessed on 29 June, 2018.

[4] Jain, A., Bansal, P., Khanna, P., "Application of Taguchi Technique to Optimize the Performance of aVibratory Bowl Feeder". Global Journal on Innovation, Opportunities and Challenges in AAI and Machine Learning, Vol. 1, pp. 13-18, Issue 1,2017.

[5] Jindal, U., Jain, S., Piyush, Khanna, P., "Graphical Analysis of a Vibratory Bowl Feeder for Clip shaped Components". IJISET - International Journal of Innovative Science, Engineering \& Technology, Vol. 4 Issue 2, pp. 279-283, February 2017.

[6] Jain, S., Jindal, U., Piyush, Khanna, P., "Mathematical Analysis of Vibratory Bowl Feeder for Clip Shaped Components". Journal of Production Engineering, Vol.20, pp. 122-126, 2017.

[7] Chauhan, A., Nirman, G., "Mathematical Analysis of U-shaped Components in a Vibratory Bowl Feeder". International Journal of Electronics, Electrical and Computational Systems, Vol. 5, Issue 4, pp. 91-99, April, 2016.

[8] Bhagat, S., Pandey, T., Garg, V., Khanna, P., "Design, Fabrication and Analysis of Vibratory Feeder". IJRMET, Vol. 4, Issue 1, pp. 73-75, November 2013 - April 2014.

[9] Bhagat, S., Pandey, T., Garg, V., Khanna, P., "Mathematical Analysis of Vibratory Bowl Feeder". International Journal of Latest Trends in Engineering and Technology, Vol 4, Issue 1, pp. 315-324, 2014. 